RिLCES ANTROPOLOGIA: SABERESYPRAOTICAS

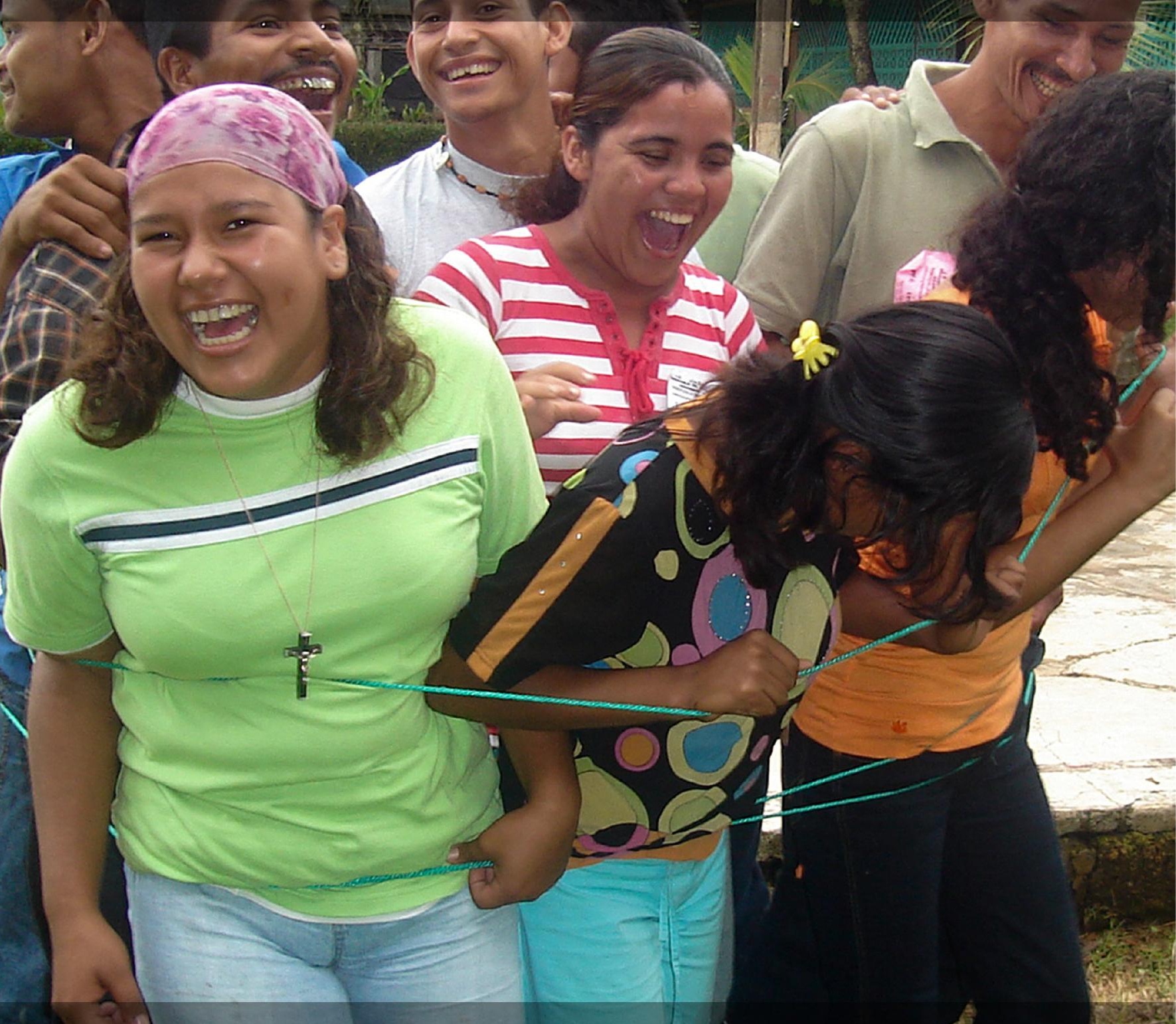

El juego es parte fundamental de los aprendizajes desde los primeros pasos del ser humano, lamentablemente muchos procesos organizativos, educativos y de investigación han renunciado al juego, siendo jugar algo tan serio y científico como cualquier otra esfera de la vida, apostemos por la recuperación de una epistelo-ludica desde la antropo-ludica. En la fotografía jóvenes aprenden jugando sobre trabajo en equipo en un taller de educación popular en Waslala -Región Autónoma de la Costa Caribe Norte - en el año 2009 


\title{
La Salud y espiritualidad desde las identidades culturales, frente al poder colonizador
}

Health and spirituality from the cultural identities, in front of the colonizing power

\author{
Anabel lbarra López \\ Departamento de Antropología \\ Universidad Nacional Autónoma de Nicaragua \\ ID Orcid: https://orcid.org/0000-0001-6539-2461 \\ anabelibarralopez@gmail.com
}

Recibido: 30-08-2018

Aceptado: 10-10-2018

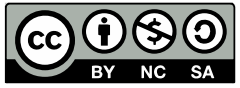

\section{Resumen}

En el siguiente ensayo se comparte una reflexión de la salud y la espiritualidad frente al poder colonizador, este ensayo es producto de diferentes vivencias y aprendizajes de formación que ha permitido articular un análisis a partir que el cuerpo es un constructo social, cultural e histórico por ende la familia, como institución primaria en nuestra vida juega un papel preponderante en la definición de las identidades.

Los significados se construye de manera recíproca y en este caso el cuerpo memoria de las emociones, el método etnográfico facilita la exposición del contenido abordar partiendo de mi propia experiencia como facilitadora de procesos de liderazgo y espiritualidad, que me ha permitido profundizar de manera teórica y práctica en mi vivencia personal y profundizar en muchos saberes ancestrales que muchas veces por no tener registros escritos solo se quedan en la memoria oral, pero que también no se reconocen como valiosos y profesionalizantes.

Palabras claves: Salud, Espiritualidad, Enfermedad, Memoria Oral, Saberes Ancestrales, Medicina Tradicional.

\section{Abstract}

In this article shares a reflection of health and spirituality front to colonizerpower, this document is a product of different experiences and learnings from training that has made it possible to articulate an analysis from which the body is one with social, cultural and historical Structo thus the family, as the primary institution in our life plays an important role in the definition of the identity. By meanings are constructed from reciprocal fashion, and in this case the body memory of emotions, so the ethnographic method facilitates exposure of the content address based on my own experience as a facilitator of processes of leads zgo and spirituality, which has allowed me to deepening theoretical and practical way in my personal experience and deepen the many ancestral knowledge that many times for not having only written records remain in the oral memory, but that also do not recognize themselves as valuable and professional.

Keywords: Health, Spirituality, Disease, Oral Memory, Ancestral Knowledge, Traditional Medicine. 


\section{Introducción}

El siguiente ensayo es titulado La Salud y espiritualidad desde las identidades culturales, frente al poder colonizador, como parte de los productos del conocimiento y reflexión de la maestría Antropología y Liderazgo del segundo cohorte, el objetivo de este es compartir algunas reflexiones en relación a nuestras identidades culturales están influenciadas por el poder colonizador y por tanto la salud y espiritualidad se ve afectada en su forma de expresarla y vivirla. Se presentan algunas reflexiones como la salud y espiritualidad, ha estado permeado de una serie de elementos arraigada de nuestras culturas, a pesar de la imposición de cultura homogeneizadora, desde un sistema de creencia único que no permite identificar y valorar los Saberes Ancestrales.

En este escrito se retoman las diferentes experiencias que se han desarrollado, las diferentes metodologías que se han implementado en base a las vivencias, procesos de reflexión, retomando los aspectos orales y de los informes desarrollados. parte de la experiencia metodológica de la educación continua que se ha desarrollado en la universidad UNAN-Managua, así como la vivencia y facilitación de la asignatura de Antropología de la salud con estudiantes. Se ha incorporado diferentes técnicas vivenciales en relacionar el cuerpo como parte de la memoria histórica y cultural.

Desde el Departamento de Antropología se ha hecho un esfuerzo de trabajar diferentes técnicas vivenciales con estudiantes, con el fin de crear confianza, fortalecer el trabajo de equipo, desarrollo de su liderazgo, así como el fortalecimiento de sus identidades individuales y colectivas.

El contexto compromete a la Antropología a entrar en ese cambio en nuestras actuaciones; que apuntan a procesos más holísticos e integradores que pueda entrar de manera crítica en nuestra conciencia y actuar cotidiano. Partiendo que la cultura es dinámica y se transforma por las diferentes historias, procesos sociales en que vive el ser humano.

\section{La salud y la espiritualidad}

A partir de los diferentes enfoques culturales se ubica la espiritualidad como un elemento importante en la cosmovisión ancestrales del ser humano es eminente- mente un ser que se construye en el día a día como un ser cultural, por ende con una cosmovisión, una identidad que en esa cotidianidad relaciona su vida espiritual en un vínculo estrecho con su salud.

A pesar de las estrategias monopolizaste y hegemónicas que establecen medidas de control y filtros como los sistemas religiosos, políticos, económicos y sociales enmascarando en el poder único; reprimen los saberes y conocimientos de manera violenta a los pueblos que a pesar de esto han resistidos mediante la práctica cultural y la historia oral

Por lo que la espiritualidad se apaga en relación al control económico de los recursos de un pueblo de abuso y desuso del poder sobre las personas asumiendo un rol de empobrecimiento y peor aún más colonizante de perdida de la espiritualidad de ese equilibrio y relación con nuestro medio, ecosistemas y seres vivos.

La relación de los sistemas vivos como el universo, esa relación cósmica que las diferentes culturas ancestrales profundizaron se ha visto en algunos casos como una locura hoy en día con mayores estudios es más evidente la progresividad de estos grandes seres humanos que lograron mediante la observación hallazgos sorprendentes.

Mi manera de ver al mundo no es solo aprendizaje individual, familiar es un aprendizaje colectivo y ancestral donde las heridas no solventadas repercuten en situaciones de violencia, heridas emocionales que construyen liderazgos enfermos, tóxicos, pero sobre todo sin valores. Como nos trae a colación este actor:

Foucault expone dos versiones del cuerpo a través del biopoder: el primero, el cuerpo como especie, es decir, el cuerpo como agente natural de reproducción (que nace, come, se reproduce y muere). El segundo, el cuerpo se convierte en un objeto que puede ser manipulado, el cuerpo como objeto de disciplina dentro de una maquinaria productiva: "el sexo... es el elemento más especulativo, más ideal y también más interior en un dispositivo de sexualidad que el poder organiza en su apoderamiento de los cuerpos, su materialidad, sus fuerzas, sus energías, sus sensaciones y sus placeres." (Foucault en Altamarin 1982:209).

Partiendo en nuestras realidades latinoamericanas encontramos una serie de aprendizajes que no hemos 


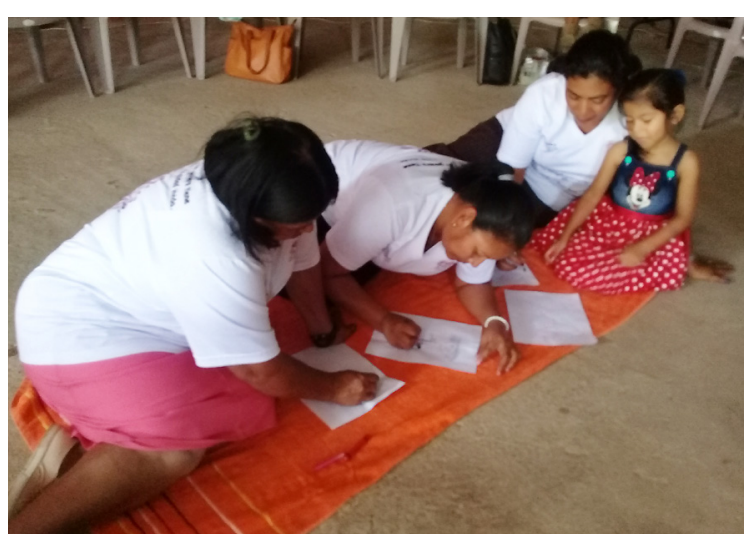

Fuente Propia: Taller de Autocuido con Mujeres Productoras Rurales de Jinotega

logrado sistematizar, pero que vale la pena revisar, profundizar en esas historias de nuestros pueblos que en nuestra vida cotidiana enfrentamos por políticas Internacionales que no, nos aportan a fortalecer las capacidades y habilidades de los pueblos, sino que nos envuelven en sus mecanismos de controles.

Este período de tiempo que vivimos es clave más allá de pensar, es debemos tener una labor emergente de reconstrucción de valores que permita fortalecer la vida humana; pero también reconectarnos con nuestras identidades culturales, relaciones colectivas, estrategias de soporte que permita desarrollar una mejor calidad de vida desde lo individual, familiar y colectivo.

Trabajar nuestra propia memoria de nuestro cuerpo para reconectarnos con nuestros dolores y sanarnos. Porque más allá de las enfermedades de los factores ambientales están las enfermedades del alma, de nuestra historia, que bloquea nuestro crecimiento, pero sobre ese trabajo del bien común.

En este sentido la Antropología de la salud, que entiende la salud en el ámbito de la cultura, comprende el trinomio salud-enfermedad-atención, como universal, frente al cual cada comunidad humana ha debido desarrollar una respuesta específica, lo que le otorga suficiente variabilidad. Estudia las dimensiones biológicas, psicológicas, culturales y sociales, que determinan el modo en que las personas entienden y viven la salud y sus problemas de salud.
Igual como pasa con una planta que no tiene suficiente, abono, falta de atención, no adecuada al clima encontramos que existen muchos seres humanos que carecen de las mismas situaciones, por lo tanto no es una planta que pueden darnos un buen fruto, sino una persona que está ahí, no logramos mayor impacto, sino que se vuelve una persona invasiva, que no aporta al fin colectivo, sino a su relación individual porque carece de esa falta de abono que le aportaría ser una persona líder y que florezca alrededor de las diferentes plantas de manera armoniosa como los ecosistema lo desarrollan.

Podemos encontrar que la naturaleza siempre está en esa búsqueda de transformación y mejora de sus condiciones; si la madre tierra se encuentra muy caliente, se da un huracán para refrescar su ambiente hace cambios muy bruscos, pero también decisiones difíciles que causan grandes caos, pero una vez que pasa viene la calma y logro cambiar a partir de iniciativa un poco dolorosa y una vez que cambia, cambia todo su entorno.

Hoy en día también encontramos mucha manipulación en la forma de ver la espiritualidad queriendo adoptar que lo de afuera es lo mejor, sin embargo, debemos de

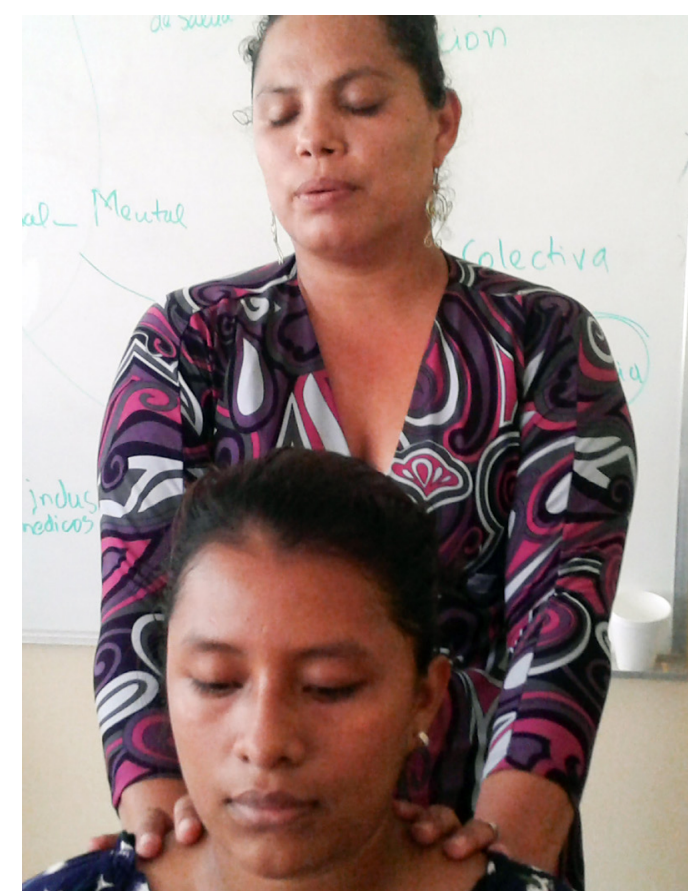

Fuente: Estudiantes de Quinto Año de Antropología Social, en el marco de la asignatura de Antropología de la Salud 
tomar decisiones de nuestra autodeterminación que tenemos como pueblo y ser respetoso de ello.

En este proceso de formación encontramos que se ha perdido tantos vínculos, como el respeto, el saludo que es parte de la cotidiana, el abrazo, la relación con las plantas con el respeto que se merece, estamos absorbidos por los medios tecnológicos nos aleja de ser escuchados, de compartir, debatir, aprender de las diferentes sabidurías. En muchos casos no sabemos ni quien es la familia y muchas veces, aunque existe se percibe un abandono.

Surgen nuevas formas de abandonos como lo es huérfanos emocionales, teniendo serios problemas de tener proyectos de vida estacado a pesar de todo el esfuerzo que desarrolla la persona.

La relación con la madre otro problema cada vez más frecuente, el tema de la planificación de hijos e hijas, la condición de su concepción de la madre no ayuda a crear vínculos de amor, sino de conflicto y por ende problemas de ovarios. Estar consciente que muchas de las enfermedades responden a las situaciones emocionales que no están resuelta que incluso causen serios problemas mentales, depresiones constantes por lo que afecta su condición de salud.

En este sentido el cumulo de situaciones no resueltas hacen que afecten la vida de pareja, familiar, educativa, laboral y el de una comunidad por las situaciones que enfrenta el ser humano que es eminentemente social.

La Humanidad no traemos «grabada» en nuestros genes la forma de ser humanos; construimos y nos construyen la forma concreta en que seremos humanos a partir de las relaciones con el grupo social en que nos formamos, a partir de las relaciones que ese grupo social concreto tiene con el entorno físico en que vive, a partir de las relaciones que el grupo tiene con el universo tanto en su práctica como en su concepción.

Nuestras relaciones productivas, nuestras relaciones con la naturaleza-alimento, nuestras relaciones sociales, los conceptos creados sobre el trabajo, la naturaleza, la sociedad, etc., forman una sola red. Y cada nudo de esa red se relaciona, tensiona, fortalece o debilita a todos los otros. A toda esa compleja red de relaciones y de conceptos la llamamos cultura. Nos cultiva, nos forma, y la cultivamos, la formamos. La relación con el medio, con la Naturaleza, no debe ser de dominio sino de integración con ella. No somos externos al medio, somos parte de la vida que existe en ese lugar y en ese tiempo que quiere y necesita desarrollarse para seguir existiendo.

\section{La Antropología nos cuestiona o nos orienta}

"La verdadera ignorancia no es la ausencia de conocimiento, Sino el hecho de rehusarse a adquirirlos"

\section{Karl Popper}

En Antropología tradicionalmente se tiene mucho cuidado en no juzgar una cultura desde los parámetros de otra. Creemos que es correcto desde el punto de vista de no considerarnos superiores las personas portadoras de una cultura, sobre las que participan en otra.

Pero consideramos que no todos los elementos de una cultura son positivos. Hay culturas que tienen muy fuerte el elemento de dominación, ya sea de la naturaleza, ya sea de los demás, y entonces es destructora. Una cultura puede llevar un camino de autodestrucción, cuando destruye su entorno y destruye el sostén que le da vida. Una cultura puede llevar un camino de destrucción de otras culturas y de otros grupos humanos y, en ese caso, habrá que buscar la manera de preservar la vida de todos los grupos.

Tal vez debemos descubrir que la «esencia» de la Humanidad, lo que nos constituye como Humanos son, no sólo las posibilidades físicas, la genética humana, sino también las relaciones Humanas y Humanizantes que seamos capaces de construir con todo el Universo. La esencia de la Humanidad sería la capacidad de tener conciencia de la Unidad Cósmica y vivir de acuerdo a esta conciencia. Implica descubrir que no venimos de una situación primigenia de perfección edénica, sino que avanzamos en un proceso de humanización que debe ser cada vez más consciente.

El contexto nos compromete que es necesario hacer cambios en nuestras actuaciones, no solo como don de la palabra sino, procesos más holísticos e integradores que pueda entrar de manera crítica en nuestra conciencia y en nuestro actuar cotidiano.

Tenemos tantos mandatos sociales que no nos permiten avanzar estamos como estáticos, esperando que otras personas resuelva nuestros problemas, sin ver que esto aportan al poder hegemónico de los pueblos, de sus familias, de nuestros países latinoamericanos. 
En nuestras culturas nicaragüenses en la profundidad de nuestra esencia encontramos la necesidad de un equilibrio entre lo material y lo espiritual, sin embargo, el entrar otros aprendizajes culturales que nos hacen alejarnos de nuestra identidad, pero sobre todo de esa sabiduría que nos hace ser consumista y nunca estar satisfecho de lo que tenemos.

La perspectiva del sociólogo italiano Franco Ferrarotti: El relato de una vida debe verse como resultado acumulado de las múltiples redes de relaciones en los que, día a día, los grupos humanos entran, salen y se vinculan por diversas necesidades. Esta manera de comprender la historia de vida nos permite descubrir lo cotidiano, las prácticas de vida abandonadas o ignoradas por las miradas dominantes, la historia de y desde los de abajo (Mallimaci F., 2006)

En la realidad que se enfrenta en la cotidianidad es necesario regresar a esos aprendizajes, por todas las condiciones que vivimos con un cambio climático, tanta violencia, con tantas personas enfermas, pero también acabando con ecosistema que hemos perdido el equilibrio y la armonía de nuestra vida.

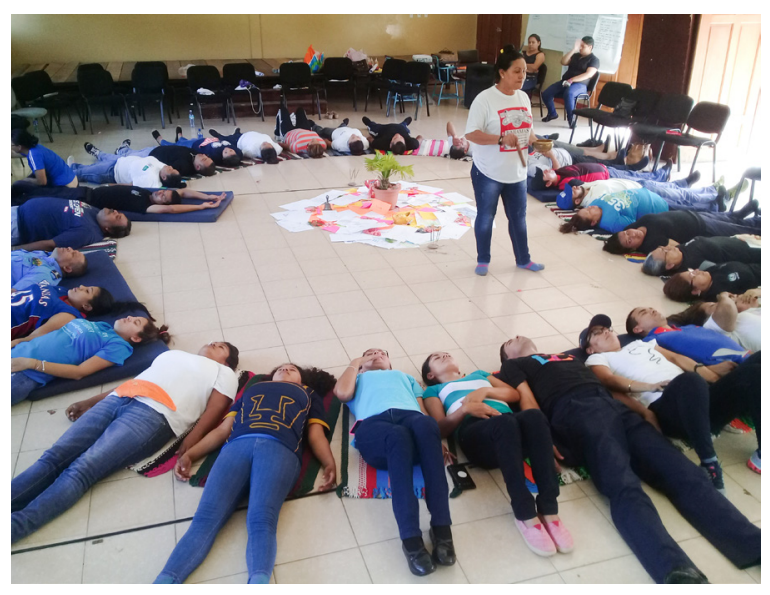

Fuente Propia : Taller de Auto cuido con oficiales de la Dirección de Asuntos juveniles, facilitado por el departamento de Antropología

Giddens habla al respecto sobre la conciencia secuestrada de los individuos. Ésta es un carácter especial de la modernidad que tiene énfasis en el control. Lo que significa la subordinación de la naturaleza para la colonización del futuro, es decir, para la planeación de los propósitos humanos a través de la ciencia y la tecnología. Lo que denomina "aparición de un sistema referencial de conocimiento de poder, que va a desembocar en el fin de la naturaleza. (Giddens 1997: 185'186).

Es importante reconocer que existe una voluntad política y jurídica en relación de atender la salud de manera holística se ha incorporado en el plan nacional de desarrollo humano, en los ejes sociales en el inciso A. Patrimonios culturales: Rescatar, proteger, salvaguardar, preservar, promover y divulgar el patrimonio histórico y cultural del pueblo nicaragüense, incluyendo prácticas culturales ancestrales.

Esto fortalece la Ley de Autonomía de la Costa Caribe, así como los diferentes pueblos indígenas de conservar sus saberes como parte de su patrimonio cultural, también en el eje de salud en todas las modalidades asume "Continuar desarrollando el Modelo de Salud Familiar y Comunitario con el protagonismo de toda la población, la red comunitaria, las familias y comunidades, fortaleciendo el trabajo a nivel local desde cada uno de los sectores".

Del mismo modo La ley de medicina Alternativa tiene una reglamentación, también cuenta con programas de atención holísticas e integradores que facilite la a tención de la medicina preventiva y de autocuidado.

Esto hace que la Antropología de la salud pueda sistematizar las diferentes experiencias y acciones que se está desarrollando; desde la labor educativa estar más consciente que la salud física se deteriora cuando no hay una salud mental, emocional y espiritual adecuado, por lo que trae daños en su autoestima, liderazgo, el trabajo en equipo, así como sus relaciones familiares y sociales.

Esto reta que la educación no debe generar cambio a nadie, sino que la persona debe de tomar conciencia de quien es y de lo que quiere ser en su vida por lo que la formación juega un rol de facilitación en los procesos de reflexión y toma de conciencia.

La educación emancipadora, por tanto, ya no ha de entenderse como una acción de unas personas sobre otras, pues sería inconsecuente con sus presupuestos básicos: "nadie educa a nadie - nadie se educa a sí 
mismo - los hombres se educan entre sí mediatizados por el mundo" (Freire, 1997, e.o. 1970, p. 73). Así, "el verdadero diálogo reúne a los sujetos en torno al conocimiento de un objeto cognoscible que actúa como mediador entre ellos" (Freire, 1990, p. 70), según CREA.

El ser humano desde la visión integradora identifica al cuerpo como memoria de las emociones, que van desde la concepción del ser humano, como en su proceso socializador que no solo se construyen en la familia, sino en los diferentes ámbitos de la vida como: la educación, comunidad, laboral, relaciones de amistades.

Reconocer los marcos legales que exiten como tal es el caso de la Ley de medicina ancestral tradicional para el revitalizamiento de los conocimientos y practicas; "Artículo 1 Objeto de la Ley. La presente ley tiene por objeto, reconocer el derecho, respetar, proteger y promover las prácticas y expresiones de la medicina tradicional ancestral de los pueblos indígenas y afro-descendientes en todas sus especialidades y el ejercicio individual y colectivo de los mismos, en función de la salud propia e intercultural y establecer las garantías adecuadas que corresponden al listado para su efectiva aplicación y desarrollo.

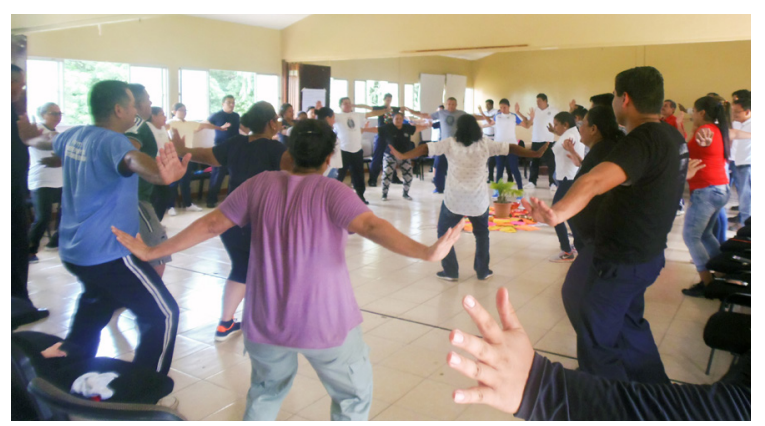

Fuente Propia : Taller de Auto cuido con oficiales de la Dirección de Asuntos juveniles, facilitado por el departamento de Antropología

\section{Conclusiones}

El equipo docente debemos de prepararnos para atender las diferentes complejidades reales de jóvenes desde sus contextos culturales, patrones de crianza, historias de vida que permita un mayor impacto en su vida, por lo tanto, en su vida profesional y compromiso con su comunidad y su país.
Ser consciente que como educadores debemos de desarrollar las potencialidades que el ser humano trae consigo mismo, para que puedan rendir, pero sobre potencie sus capacidades, habilidades y valores.

Potenciar que el estudiantado se integre a la vida social, desde sus contextos socioculturales, con sus saberes, identidades, liderazgo fluyendo en sus capacidades y habilidades para su vida, dado que estas situaciones emocionales afecta el proceso de aprendizaje.

Se hace necesario no solo mantener viva los saberes desde la tradición oral, sino también profundizar mediante la investigación para fortalecer las estrategias y programas de plan de desarrollo humano de Nicaragua. Por lo que ha sido clave Conocer e interpretar la cultura y la realidad social permite posicionarse en la dimensión antropológica como un área del conocimiento de referencia nacional con base en el desarrollo del conjunto docencia-investigación-extensión desde una visión flexible, crítica, abierta a la diversidad. Esto obliga a una práctica ética basada en la franqueza, la responsabilidad de profesionales éticos y con valores con las comunidades y su población.

Para alcanzar la extensión universitaria se necesita de la validación y devolución de las investigaciones de los actores sociales, que son portadores de valores intangibles como la identidad, la cosmovisión, con una perspectiva basada en la reflexión permanente y la explicación que, como ciencia aporta, y a su vez va generando en el proceso de ampliación y, en otros casos, profundización de conocimientos útiles y aplicables al mejoramiento de la calidad de vida de la población.

El método etnográfico nos permite hacer una descripción de acuerdo a la técnica de observación directa que permite tener una fotografía de acuerdo a los contextos y los procesos vividos. En este caso hacer una descripción de la vivencia y lo observado desde la perspectiva de la Antropología de la salud. 


\section{Referencias}

Mallimaci F., G. B. (2006). Historias de vida y método biográfico. Estrategias de Investigación cualitativa, Barcelona, Gedisa, 2-6.

Foucault, Michell (1978). Cuarta y quinta conferencia. La verdad jurídica y las formas judiciales. Gedesia 2000. Barcelona.

- (1976). Derecho de muerte y poder sobre la vida" Historia de la sexualidad. 1 la voluntad de saber. Siglo XXI. Madrid.
- (1992). Undécima lección- 17 de marzo de 1996. Genealogía del racismo. LaPiqueta. Madrid.

Giddens, Anthony (1997). Modernidad, identidad y el yo. El yo en y la sociedad Contemporánea. Editorial Península. Barcelona.

\section{Anabell Carolina lbarra López}

Maestría en Antropología y Liderazgo. Especialista en derecho de la niñez, adolescencia y juventud en el Desarrollo comunitario. Diplomada en incidencia y cultura de paz. Posgrado en Teología y Democracia. Diplomada en Biodanza, Licenciatura en Antropología social

Experiencia metodológica de trabajo con juventud, desarrollo y poder local. Metodología de trabajo con género. Experiencia investigativa y consultoría en temas de VIH, juventud y liderazgo, perspectiva de género, Amplio conocimiento y manejo laboral en áreas incidentes de Poder local, sistematización y movimiento de mujeres organizadas.

Actualmente se dedica a la docencia universitaria, en asignaturas como antropología de la Salud, Taller de Investigación Antropológica y Antropología de género también en diplomados y cursos sobre metodología de educación popular y herramientas y técnicas para la organización y educación 